\title{
CYP24A1-induced vitamin D insufficiency promotes breast cancer growth
}

\author{
MAKOTO OSANAI and GANG-HONG LEE \\ Department of Pathology, Kochi University School of Medicine, Nankoku, Kochi 783-8505, Japan
}

Received April 19, 2016; Accepted August 16, 2016

DOI: $10.3892 /$ or.2016.5072

\begin{abstract}
Vitamin D plays a critical role in tissue homeostasis by regulating the expression of genes affecting cell proliferation, differentiation, and apoptosis. The vitamin D 24-hydroxylase CYP24A1 functions in vitamin D target tissues to degrade the hormonal form of vitamin D. Existing knowledge regarding dysregulated CYP24Al expression supports its candidacy as a putative oncogene. Here, we found that the suppression of constitutive $C Y P 24 A 1$ expression conferred target cells with increased susceptibility to apoptosis and consequently inhibited anchorage-independent growth in breast carcinoma cells. In addition, suppression of vitamin D metabolism following knockdown of CYP24A1 significantly reduced tumor growth in vivo. These data provide substantial evidence for a pro-survival and stimulatory oncogenic effect of CYP24A1 in breast carcinoma cells.
\end{abstract}

\section{Introduction}

Oncogene activation plays a critical role in the development of human malignancies. Chromosome 20q13.2 shows frequent aberrations in various cancers, and an increased copy number in this region has been observed in breast cancer (1). The results from cytological studies have identified several putative oncogenes that reside within a $\sim 2-\mathrm{Mb}$ region associated with recurrent amplifications at $20 \mathrm{q} 13.2$ in $12 \%$ of primary breast tumors $(2,3)$. In addition, high-level amplification of $20 q 13.2$ significantly associates with the histological grade of breast cancers and shorter disease-free survival (4). Mapping of the 20 q13 amplicon found in breast cancers by high-resolution analysis of comparative genomic-hybridization arrays identified $C Y P 24 A 1$ as the driver for $20 \mathrm{q} 13$ amplification, suggesting that $C Y P 24 A 1$ is a potential oncogene $(1,5)$.

Correspondence to: Dr Makoto Osanai, Department of Pathology, Kochi University School of Medicine, Kohasu, Oko-cho, Nankoku, Kochi 783-8505, Japan

E-mail: osanaim@kochi-u.ac.jp

Key words: breast cancer, vitamin D, CYP24A1, oncogene, tumorigenicity
The vitamin D 24-hydroxylase CYP24A1 functions specifically in the metabolic inactivation of $1 \alpha, 25$-dihydroxyvitamin D3 $\left(1 \alpha, 25(\mathrm{OH})_{2} \mathrm{D}_{3}\right)$, the hormonally active form of vitamin $\mathrm{D}$. The $1 \alpha, 25(\mathrm{OH})_{2} \mathrm{D}_{3}$ form of vitamin $\mathrm{D}$ serves as a ligand for the vitamin $\mathrm{D}$ receptor and maintains tissue homeostasis by regulating the expression of genes affecting cell proliferation, differentiation, and apoptosis (6). Vitamin D bioavailability, which is regulated by a coordinated balance between $1 \alpha, 25(\mathrm{OH})_{2} \mathrm{D}_{3}$ biosynthesis and catabolism, determines cellular responses to vitamin D. CYP24A1 expression restricts the access of $1 \alpha, 25(\mathrm{OH})_{2} \mathrm{D}_{3}$ to the transcriptional machinery by converting $1 \alpha, 25(\mathrm{OH})_{2} \mathrm{D}_{3}$ to rapidly excreted inactive derivatives, which limits vitamin D signaling within cells. Accumulating evidence has shown that a wide spectrum of vitamin D metabolites, such as $1 \alpha, 24,25-(\mathrm{OH})_{3} \mathrm{D}_{3}$ and $24-\mathrm{oxo}-1 \alpha, 25-(\mathrm{OH})_{2} \mathrm{D}_{3}$, are detectable in different types of tumor cells, and CYP24A1 expression is elevated in various cancers and correlates both with dedifferentiation and poor prognosis (7-9).

The relationship between cellular vitamin D bioavailability and tumorigenesis is compelling, and the existing knowledge regarding dysregulated $C Y P 24 A 1$ expression supports its candidacy as a putative oncogene. Indeed, previous data revealed that the knockdown of $C Y P 24 A 1$ in MDA-MB-231 cells by antisense oligonucleotides resulted in reduced proliferation and inhibited colony formation (10). However, the underlying mechanism whereby vitamin D depletion through cellular metabolic processes contributes to increased susceptibility to carcinogenic insults remains to be defined. Here, we investigated whether the manipulation of $C Y P 24 A 1$ expression modulates the tumorigenicity of breast carcinoma cells. The data suggest that CYP24A1-mediated vitamin D metabolism promotes cell survival and breast cancer growth.

\section{Materials and methods}

High-performance liquid chromatography (HPLC). To examine the metabolic activity of CYP24A1 in the event of CYP24A1 manipulation, normal phase HPLC analysis was performed using ${ }^{3} \mathrm{H}$-labelled $1 \alpha, 25(\mathrm{OH})_{2} \mathrm{D}_{3}$ on an Alliance 2695 separation module, equipped with a 996 photodiode array detector (Waters, Milford, MA, USA), as described elsewhere in detail (11).

Cell culture and transfection. The breast cancer cell lines MCF7 and MDA-MB-231 were obtained from a local 
distributor (Summit Pharmaceuticals International, Tokyo, Japan) of the American Type Culture Collection (Manassas, VA, USA). MCF7 cells are estrogen receptor (ER)-positive cells, and MDA-MB-231 cells are ER-negative cells. All cells were maintained in Dulbecco's modified Eagle's medium (Sigma, St. Louis, MO, USA) supplemented with $10 \%$ fetal bovine serum (FBS) (Invitrogen, Carlsbad, CA, USA), 100 U/ $\mathrm{ml}$ penicillin, and $100 \mu \mathrm{g} / \mathrm{ml}$ streptomycin (Sigma).

Cells were transfected with different types of CYP24A1specific small-hairpin RNA (shRNA)-expressing lentivirus plasmids (Sigma) using FuGENE6 (Roche, Basel, Switzerland) to generate stable transfectants. Transfected clones were selected in $0.6 \mu \mathrm{g} / \mathrm{ml}$ puromycin (Sigma). Drug-resistant clones were picked after more than 14 days of selection and screened for CYP24A1 expression. We obtained the following MDA-MB-231 cell transfectants: CYP24A1 shRNA \#1296 (harboring shRNA clone NM_000782.2-1296s1c1) and CYP24A1 shRNA \#1016 and CYP24A1 shRNA \#1016S (harboring shRNA clone NM_000782.2-1016s1c1).CYP24A1shRNA \#1016S is a transfectant originating from a single clone that showed efficient suppression of constitutive CYP24A1. A negative-control shRNA was used as a control. Cells were also transfected with $C Y P 24 A 1$-specific small-interfering RNAs (siRNAs; Santa Cruz Biotechnology, Santa Cruz, CA, USA), or a plasmid containing the full-length $C Y P 24 A 1 \mathrm{cDNA}$ (OriGene, Rockville, MD, USA).

Semiquantitative reverse transcription-polymerase chain reaction (RT-PCR) analysis. Total RNA was extracted using the TRIzol reagent (Invitrogen), and subsequent RT-PCR was performed using the Superscript II Reverse Transcriptase kit (Invitrogen). Samples were incubated at $42^{\circ} \mathrm{C}$ for $50 \mathrm{~min}$, after which the reactions were terminated by incubation at $70^{\circ} \mathrm{C}$ for $15 \mathrm{~min}$. Then, the cDNA was incubated with $0.5 \mathrm{U}$ of Taq DNA polymerase (Takara, Shiga, Japan) and appropriate primers to amplify the genes of interest. The cycling conditions were as follows: $20-40$ cycles of $30 \mathrm{sec}$ at $96^{\circ} \mathrm{C}, 30 \mathrm{sec}$ at $58^{\circ} \mathrm{C}$, and $1 \mathrm{~min}$ at $72^{\circ} \mathrm{C}$, followed by a final elongation time of $7 \mathrm{~min}$ at $72^{\circ} \mathrm{C}$. The sequences of the PCR primers used are available upon request. The expression of each gene of interest was analyzed using cycling parameters that were optimized previously for detection linearity, allowing for semiquantitative analysis of signal intensities. PCR experiments were repeated in 3 independent experiments to ensure that the quantified expression was reproducible. Densitometric analyses of gel bands were performed using ImageJ software (National Institutes of Health, Bethesda, MD, USA).

Microarray analysis. Gene-expression changes caused by CYP24Al suppression were examined by microarray analysis. Total RNA was analyzed using the Agilent Whole Human Genome Oligo Microarray (4x44K; Agilent Technologies, Santa Clara, CA, USA). Gene-expression analysis was outsourced to Bio Matrix Research (Chiba, Japan). Briefly, total RNA (100 ng) was converted into cDNA, and complimentary RNA (cRNA) was synthetized by in vitro transcription and subsequently labeled with cyanine 3-CTP and cyanine 5-CTP, using the Low Input Quick Amp Labeling kit. Labeled cRNA was hybridized with a microarray chip for $17 \mathrm{~h}$ using the Gene Expression Hybridization kit, and slides were scanned using an Agilent Microarray Scanner and Feature Extraction Software 9.5, with default settings. Raw data were normalized using the Quantile algorithm of the Gene Spring Software package, version 11.0 (all from Agilent).

Western blot analysis. Aliquots of whole cell lysates $(20 \mu \mathrm{g})$ were separated on $12 \%$ sodium dodecyl sulfate-polyacrylamide gels and electroblotted onto nitrocellulose membranes. Membranes were then immunoblotted with antibodies against CYP24A1 (sc-32166; 1:50, Santa Cruz Biotechnology), the cleaved form of caspase-3 (sc-22171-R; 1:75, Santa Cruz Biotechnology), Pdlim2 (SAB1407872; 1:100, Sigma), and $\beta$-actin (A5316; 1:1,000, Sigma). The membranes were incubated with appropriate peroxidase-labeled secondary antibodies (1:2,000, Dako, Glostrup, Denmark), and bands were visualized using enhanced chemiluminescence (GE Healthcare, Buckingham, UK).

Apoptosis and anoikis induction. Oxidative stress-induced apoptosis was stimulated by incubating cells in $0-100 \mu \mathrm{M}$ $\mathrm{H}_{2} \mathrm{O}_{2}$ for $24 \mathrm{~h}$. Anoikis was induced by adding MDA-MB-231 cells to agarose-coated dishes to avoid cell attachment in the presence or absence of $100 \mathrm{nM} 1 \alpha, 25(\mathrm{OH})_{2} \mathrm{D}_{3}$ (Sigma).

Deoxynucleotidyl transferase-mediated nick end labeling (TUNEL) and cell-proliferation assays. Apoptosis was assessed in cells cultured on collagen-coated glass coverslips by performing TUNEL assays. In addition, tumor tissues developed in mice were fixed in $70 \%$ methanol and studied in TUNEL assays. Apoptotic cells were visualized using an In Situ Cell Death Detection kit (11684817910; M7240, Roche). The procedure was also performed without terminal deoxynucleotidyl transferase, as a negative control. To examine the cell-proliferation rate, cells were manually counted every $24 \mathrm{~h}$ up through day 7 after an equal number of cells had been plated. In addition, cellular DNA synthesis was assessed by immunohistochemical labeling of Ki-67 (MIB-1 clone; 1:100, Dako). The cells of interest were counted under a light microscope under low magnification (x100) in 10 randomly selected fields in each section. The results were confirmed in triplicate independent analyses.

Colony-forming assays. Soft agar assays were performed in 6 -cm dishes to assess colony formation in 3 dimensions. Cells $\left(2.5 \times 10^{3}\right)$ were uniformly suspended in $6 \mathrm{ml}$ of $0.33 \%$ agarose gel with growth medium supplemented with 5\% FBS and then overlaid onto the base layer of $1 \%$ agarose gel. Plates were incubated for at least 3 weeks, and cell clusters approximately $>50 \mu \mathrm{m}$ in diameter were defined as positive. Colonies developing on cell culture dishes in soft agar suspensions were counted using phase-contrast microscopy under low magnification (x100) in 10 separate random fields in each plate. For quantitative analysis, the number of colonies formed by control cells was defined as $100 \%$.

Tumor growth in vivo. We injected cells of parental MDA-MB-231 and its transfectants ( $2 \times 10^{5}$ cells in $50 \mu 1 /$ mouse $)$ into the mammary fat pads of 6 or 7-week-old female athymic nude mice (Charles River Japan, Yokohama, Japan). Animals were euthanized when skin ulceration of the primary tumor 

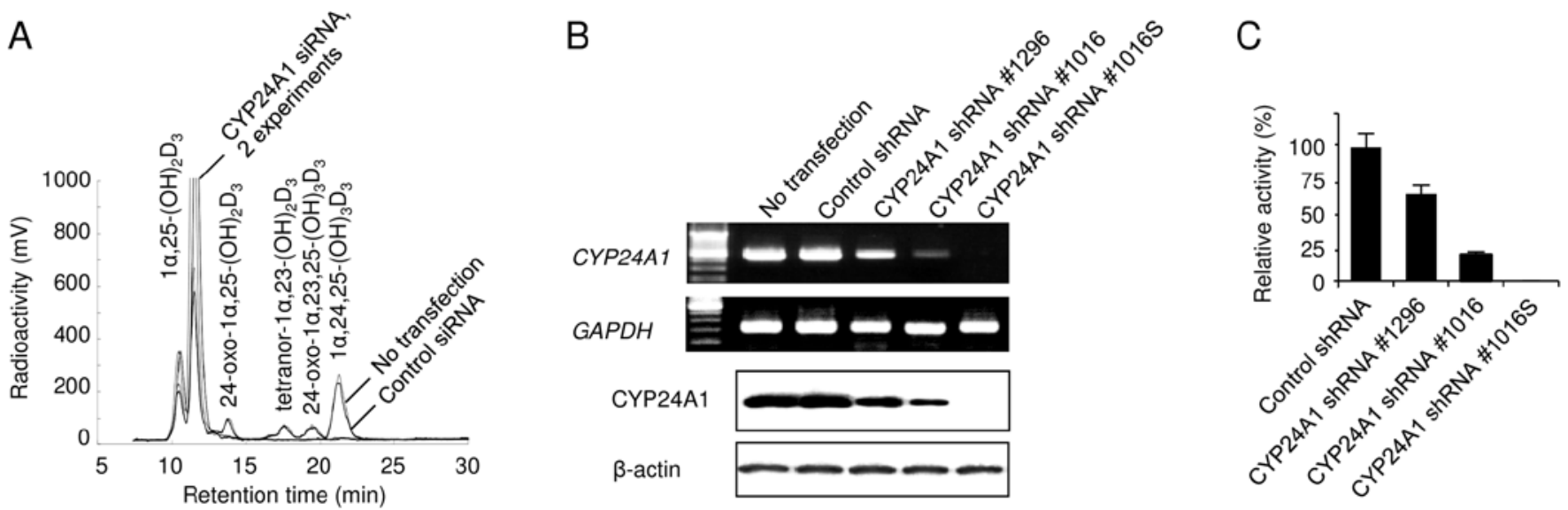

Figure 1. Establishment of CYP24A1-suppressed cell lines. (A) HPLC analysis to examine the metabolic activity of $1 \alpha, 25(\mathrm{OH})_{2} \mathrm{D}_{3}$. MDA-MB-231 cells were transfected with CYP24A1-specific siRNAs, and vitamin D metabolic activities were examined by HPLC at $48 \mathrm{~h}$ post-transfection. No metabolites were detected when cells were transfected with CYP24A1-specific siRNAs in 2 independent experiments. (B) Expression of CYP24A1 in MDA-MB-231 cells transfected with different CYP24A1-specific shRNAs. (C) Metabolic activity of $1 \alpha, 25(\mathrm{OH})_{2} \mathrm{D}_{3}$ in each transfectant. The summation of peak radioactivity from all metabolites as shown in (A) was analyzed by HPLC and expressed as the relative metabolic activity. Note the various suppression levels of vitamin D metabolic activity, which closely correlated with the CYP24A1 expression levels.

occurred. Tumor volumes were calculated in 2 dimensions in a time-dependent manner, after the inoculation of cells in independent duplicate experiments. The volume $(\mathrm{V})$ of the primary tumors was calculated by the following equation: $V=(\pi / 6) \mathrm{x}$ $(\mathrm{L} \mathrm{x} \mathrm{W})^{2}$, where $\mathrm{L}$ is the length representing the largest tumor diameter and $\mathrm{W}$ is the perpendicular width of tumors. We examined primary tumors macroscopically for the formation of tumors, and then the tumors were subjected to histological evaluations. The maintenance and handling of animals were conducted using protocols approved by the Animal Care Committee of Kochi University School of Medicine.

Statistical analysis. Unless otherwise specified, all data are expressed as means \pm standard deviations from at least 3 independent experiments, each performed in triplicate wells. Statistical differences were analyzed using Student's t-test. A P-value of $<0.05$ was considered statistically significant.

\section{Results}

Establishment of CYP24A1-silenced cells. We transfected MDA-MB-231 cells with siRNAs against $C Y P 24 A 1$ to examine the suppressive effect of $C Y P 24 A 1$ silencing on vitamin D metabolism by HPLC analysis (Fig. 1A). We also transfected different types of CYP24A1-specific shRNAs into MDA-MB-231 cells to establish several different stable transfectants with various CYP24A1 expression levels. Although our preliminary observations revealed that the phenotypes of at least 3 independent clones were similar, the cell populations were mixed to establish a stably transfected cell line to avoid possible clonal variation within the clonal transfectants. Finally, we obtained pools of transfectants, designated as CYP24A1 shRNA \#1296 and CYP24A1 shRNA \#1016. To select for clones with more specific phenotypes, we generated a clonal transfectant designated as CYP24A1 shRNA \#1016S, which was isolated following independent transfections and subsequent screening for low CYP24A1 expression. CYP24Al expression was lower in the shRNA transfectants, compared to the constitutive $C Y P 24 A 1$ expression observed in control cells (Fig. 1B). CYP24Al expression was significantly lower in CYP24A1 shRNA \#1016 cells than in CYP24A1 shRNA \#1296 cells. A striking effect of CYP24A1-specific shRNA was observed in CYP24A1 shRNA \#1016S cells, which showed no detectable CYP24A1 protein expression. In addition, the CYP24A1 expression level was closely correlated with the metabolism of $1 \alpha, 25(\mathrm{OH})_{2} \mathrm{D}_{3}$ in each transfectant (Fig. 1C).

CYP24A1 suppression alters the gene-expression profile. We examined alterations in the gene-expression profile following CYP24Al suppression, using microarray analysis to test the possibility that mRNAs induced or suppressed by $C Y P 24 A 1$ silencing were responsible for the tumor pathology (Fig. 2). Breast tumors expressing hormone receptors, such as ER, generally display a less aggressive phenotype and are associated with prolonged disease-free and overall survival. To exclude the possibility that the hormone receptor status might affect the tumor pathology, we examined gene-expression alterations following shRNA-mediated stable CYP24A1 silencing, both in ER-positive MCF7 cells and ER-negative MDA-MB-231 cells, although these cell lines show different oncogenic behaviors. We found that the changes in geneexpression patterns between these cell types were different, but at least shared some similarities (Fig. 2A). CYP24Al silencing affected the expression of an extensive range of oncogenic pathway members, including oncogenes, tumor-suppressor genes, and components of the apoptosis machinery (Fig. 2B and $\mathrm{C}$ ). We also observed altered signaling in pathways mediating cell growth and differentiation, as well as with a variety of signal-transduction molecules. As evidenced by the altered expression of cell-adhesion molecules, CYP24A1 suppression may affect the tumor microenvironment and tumor cell-interstitial cell interactions. Signaling regulating angiogenesis was also modulated by silencing CYP24A1 expression. Further, our data provided evidence of the possible association 
A

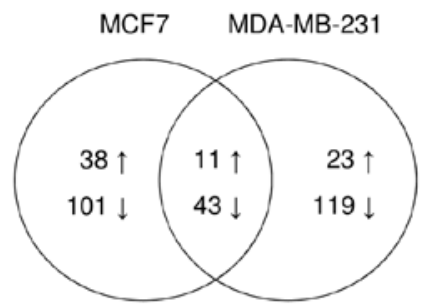

C
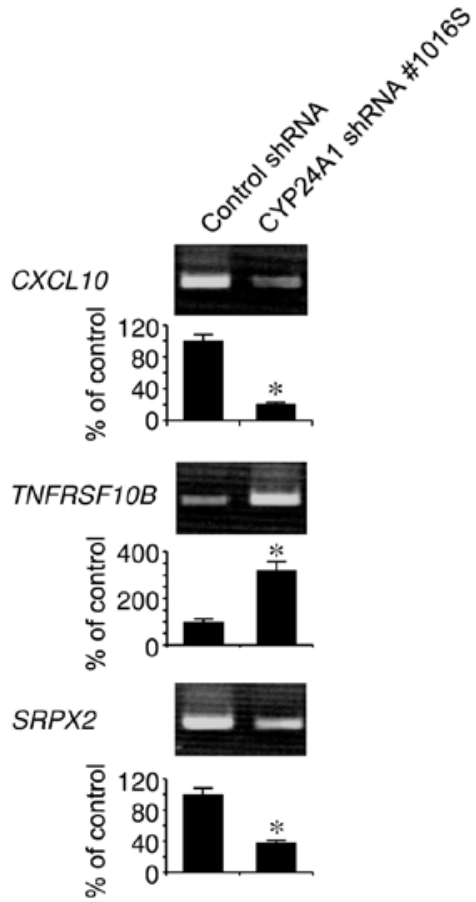

PLAU

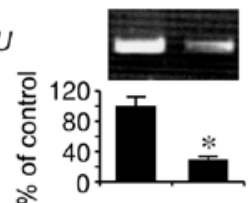

$G A P D H$

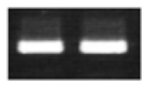

B

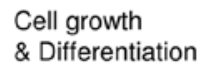

D

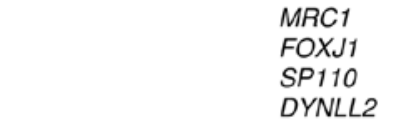

Apoptosis \& Cell senescence

CCL2

CCLS

CCL20

TNFRSF6

SEMA4D

TNFRSF10B

TNFSF18

BIRC5

CFLAR

MYBL2

FOXO1

ONECUT2

Signal transduction molecules

MYLS

MYLK

KRT7

KRT17

PTGIS

SRPX2

SIRPA

TRPV 3

CIB2

PIK3R5

Cell-cell adhesion molecules

\section{MCAM \\ CD44 \\ ICAM1 \\ VCAM1 \\ MTSS1 \\ ITGB4}

Angiogenesis

ANGPT1

IGF1

PLAU

FLT1

ESM1

HGF

Invasion

\& Metastasis

MMP1

MMP2

MMP9

SNAIL

BMP7

TIMP1

TWIST2

LRRC15

PDLIM2

AQP3

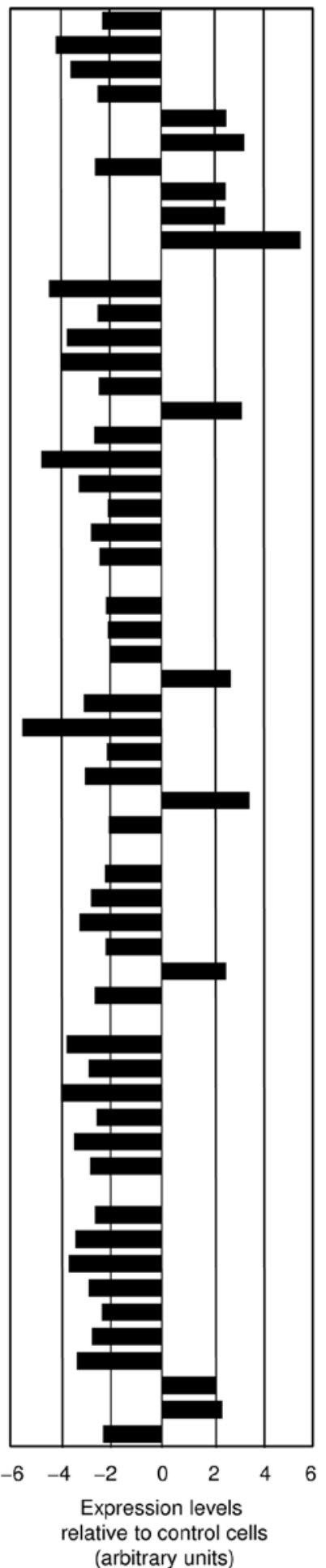

(arbitrary units)

Figure 2. CYP24A1 expression affects a wide array of signaling pathways involved in carcinogenesis. (A and B) Venn diagram representing the number of shared and cell-type specific changes caused by CYP24A1 suppression in MCF7 and MDA-MB-231 cells (A). The numbers indicate genes whose expression increased or decreased by an average $\geq 200 \%(n=2)$, and the overlapping circles indicate the number of dysregulated genes observed in both cell lines. Genes were manually grouped according to function, and all genes that showed altered expression levels in both MCF7 and MDA-MB-231 cells are displayed graphically, representing the mean expression values observed in both cell types (B). (C) Verification of the results of microarray analysis by RT-PCR in MDA-MB-231 cells, and quantitative analysis of gene-expression changes. " $\mathrm{P}<0.05$ for control cells. (D) Verification of gene-expression alterations of PDLIM2 in MDA-MB-231 cells transfected with various constructs, as indicated.

of CYP24Al downregulation with gene families involved in tumor cell invasion and metastasis, such as different types of matrix metalloproteinases. PDLIM2 expression was also asso- ciated with CYP24Al expression (Fig. 2D), which is consistent with previous data showing that PDLIM2 expression is driven by vitamin $\mathrm{D}$ (12). The alteration of gene expression observed 

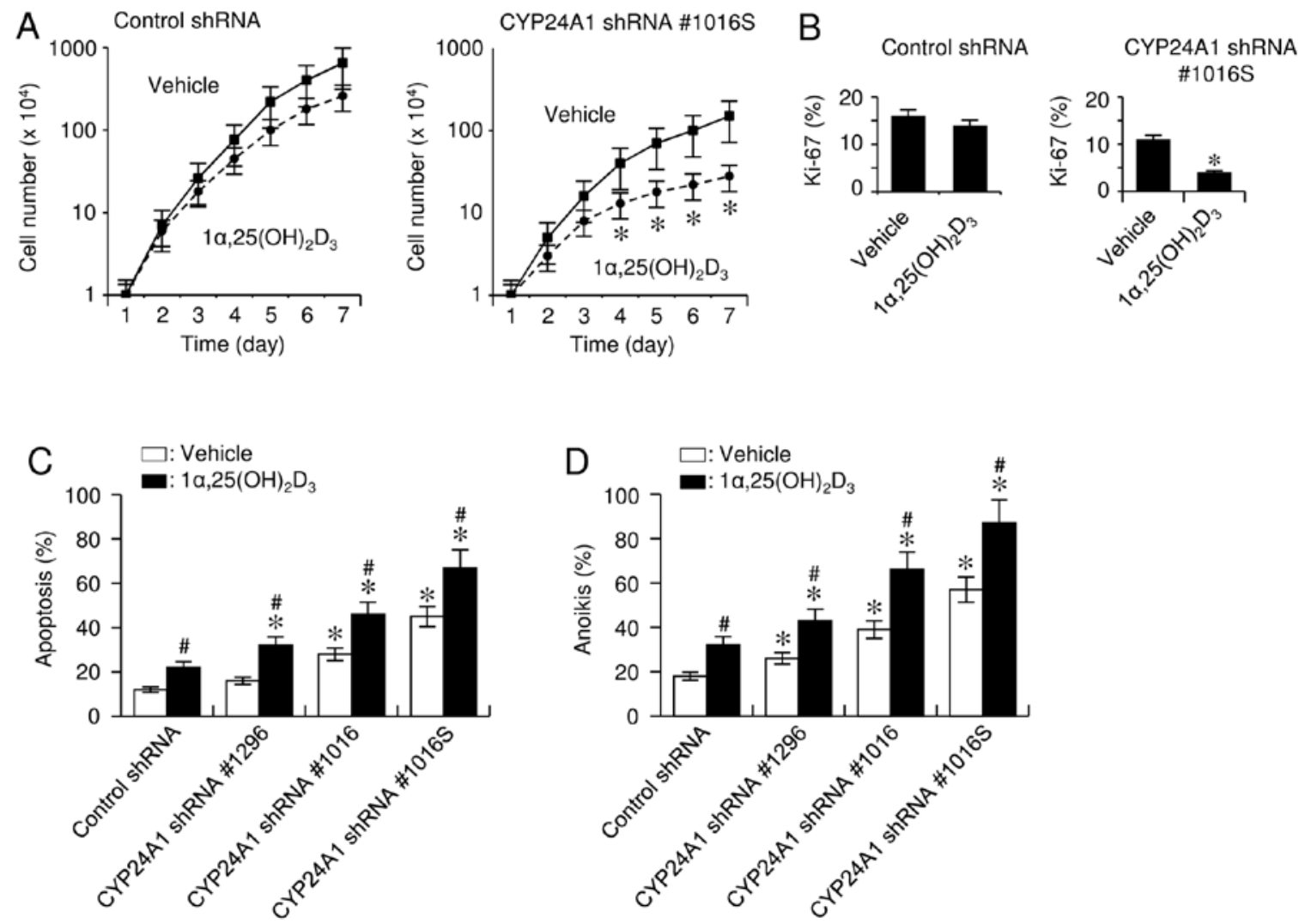

Figure 3. Suppression of $C Y P 24 A 1$ expression inhibits cell growth and promotes apoptosis. MDA-MB-231 cells were exposed to $100 \mathrm{nM} 1 \alpha, 25(\mathrm{OH})_{2} \mathrm{D}_{3}$ or vehicle control in cells transfected with CYP24A1-specific or negative-control shRNA. (A) Cell proliferation. (B) Ki-67 labeling of cells. (C) Apoptosis was examined with a 24-h exposure to $50 \mu \mathrm{M} \mathrm{H}_{2} \mathrm{O}_{2}$. (D) Anoikis was induced after adding MDA-MB-231 cells to agarose-coated dishes to avoid cell attachment. $\mathrm{P}<0.05$ for control cells vs. cells treated with $1 \alpha, 25(\mathrm{OH})_{2} \mathrm{D}_{3}(\#)$. ${ }^{*} \mathrm{P}<0.05$ for control cells vs. cells transfected with $C Y P 24 A 1-$ specific shRNA.

suggested that many of the genes involved in cancer-related pathways are modulated to favor cell survival when $C Y P 24 A 1$ is constitutively expressed.

CYP24A1 suppression inhibits cell growth and provokes apoptosis. To investigate the effect of CYP24A1 signaling on cell proliferation, cell numbers were analyzed in a time-dependent manner. Manual cell counting revealed an appreciable, but not significant reduction in cell growth, regardless of the presence of $1 \alpha, 25(\mathrm{OH})_{2} \mathrm{D}_{3}$. However, $C Y P 24 A 1$-silenced cells that were exposed to $1 \alpha, 25(\mathrm{OH})_{2} \mathrm{D}_{3}$ exhibited significantly decreased cell growth (Fig. 3A) and DNA-synthesis rates (Fig. 3B).

We also examined the effect of altered $C Y P 24 A 1$ expression on apoptosis because $1 \alpha, 25(\mathrm{OH})_{2} \mathrm{D}_{3}$ is known to exert pro-apoptotic effects in cells (6). When cells were incubated under oxidative stress caused by $\mathrm{H}_{2} \mathrm{O}_{2}$, TUNEL assay results consistently revealed that $1 \alpha, 25(\mathrm{OH})_{2} \mathrm{D}_{3}$ treatment enhanced the sensitivity of cells to $\mathrm{H}_{2} \mathrm{O}_{2}$-induced cell death, and CYP24A1 suppression conferred a significant increase in sensitivity to apoptosis (Fig. 3C). The CYP24Al expression level inversely correlated with the apoptosis-sensitizing effect caused by $1 \alpha, 25(\mathrm{OH})_{2} \mathrm{D}_{3}$, suggesting that the catabolic activity of the enzyme was important for apoptosis sensitivity. In addition, cells with downregulated $C Y P 24 A 1$ expression gained increased sensitivity to anoikis, and $1 \alpha, 25(\mathrm{OH})_{2} \mathrm{D}_{3}$ enhanced this effect (Fig. 3D).

Although we observed that the basal levels of cell growth and apoptosis differed between the control- and CYP24A1-
shRNA transfectants, there was evidence that normal FBS contained active concentrations of various growth and differentiation factors, including $1 \alpha, 25(\mathrm{OH})_{2} \mathrm{D}_{3}$, which can modulate the transcriptional machinery driven by these biologically relevant factors (13). This finding was also explained by the observation that basal levels of cell growth and apoptosis were unchanged following $C Y P 24 A 1$ suppression in media supplemented with charcoal-dextran-treated FBS (data not shown). These data indicated that the expression level of CYP24A1 contributes to determine the sensitivity of cells to apoptosis.

CYP24A1 suppression inhibits tumorigenic potency in vitro. Consistent with the apoptosis-sensitizing effect of CYP24Al inhibition, CYP24A1 downregulation significantly suppressed colony formation in soft agar, as evidenced by a decreased number and size of colonies (Fig. 4A and B). Treatment with $1 \alpha, 25(\mathrm{OH})_{2} \mathrm{D}_{3}$ inhibited anchorage-independent growth, and this effect was more evident following CYP24Al suppression (Fig. 4A). Our observations suggested that the expression level of $C Y P 24 A 1$ was significantly associated with the colony-formation capability of cells, supporting that CYP24A1 expression had a stimulatory oncogenic effect on breast carcinoma cells.

CYP24A1 suppression abrogates tumorigenicity in vivo. To address whether CYP24Al affects tumorigenicity in vivo, we employed an orthotopic-transplantation mouse model. CYP24A1 suppression inhibited tumorigenicity in vivo, 


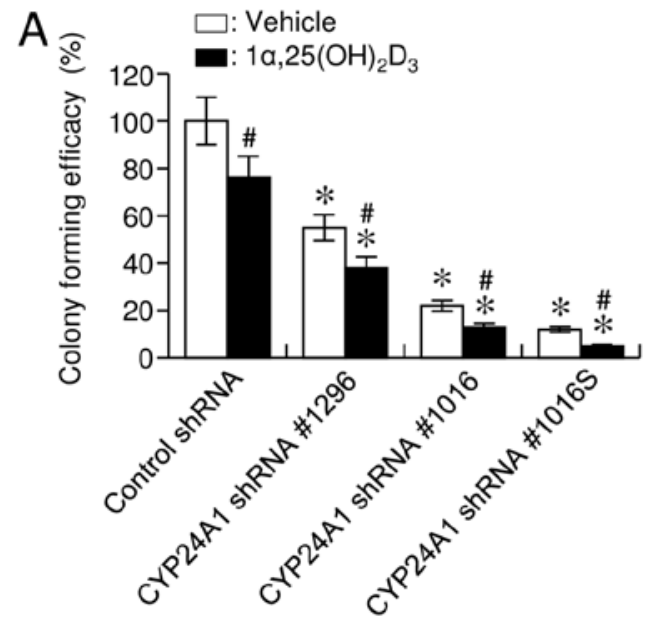

B
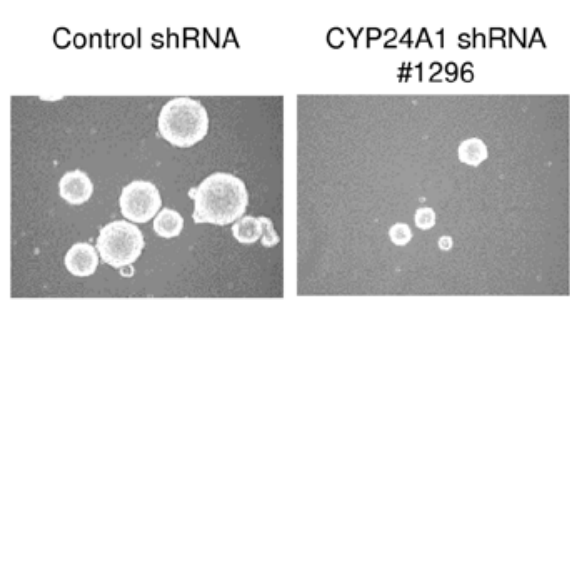

CYP24A1 ShRNA \#1016S

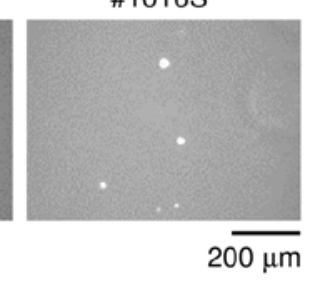

Figure 4. Suppression of CYP24A1 expression inhibits anchorage-independent growth. MDA-MB-231 cells were exposed to $100 \mathrm{nM} 1 \alpha, 25(\mathrm{OH})_{2} \mathrm{D}_{3}$ or vehicle control following transfection with CYP24A1-specific or negative-control shRNA. (A and B) CYP24A1 suppression decreased colony formation in soft agar. Quantification of colony numbers (A) and representative morphology of the colonies (B). $\mathrm{P}<0.05$ for control cells vs. cells treated with $1 \alpha, 25(\mathrm{OH})_{2} \mathrm{D}_{3}(\#)$. ${ }^{*} \mathrm{P}<0.05$ for control cells vs. cells transfected with CYP24A1-specific shRNA.

A

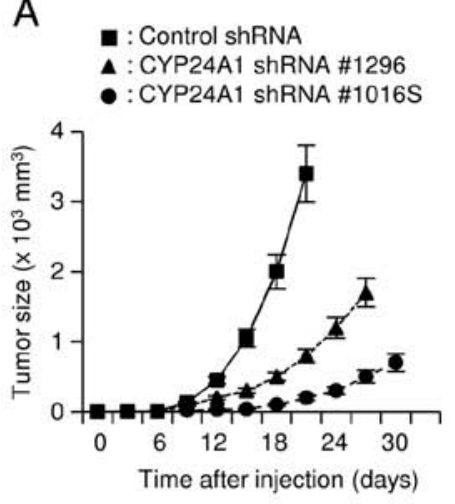

$\mathrm{D}$

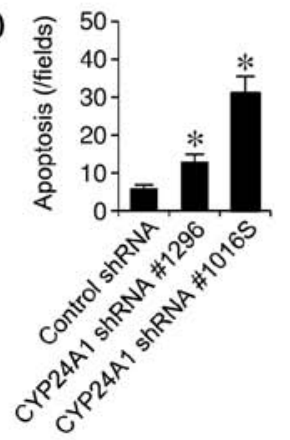

B
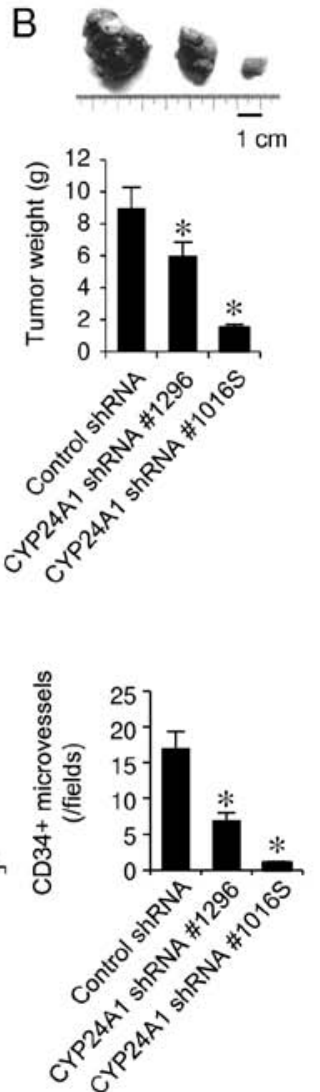

C

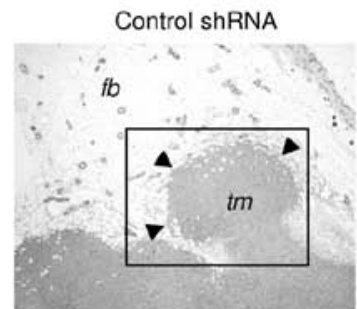

CYP24A1 ShRNA \#1016S
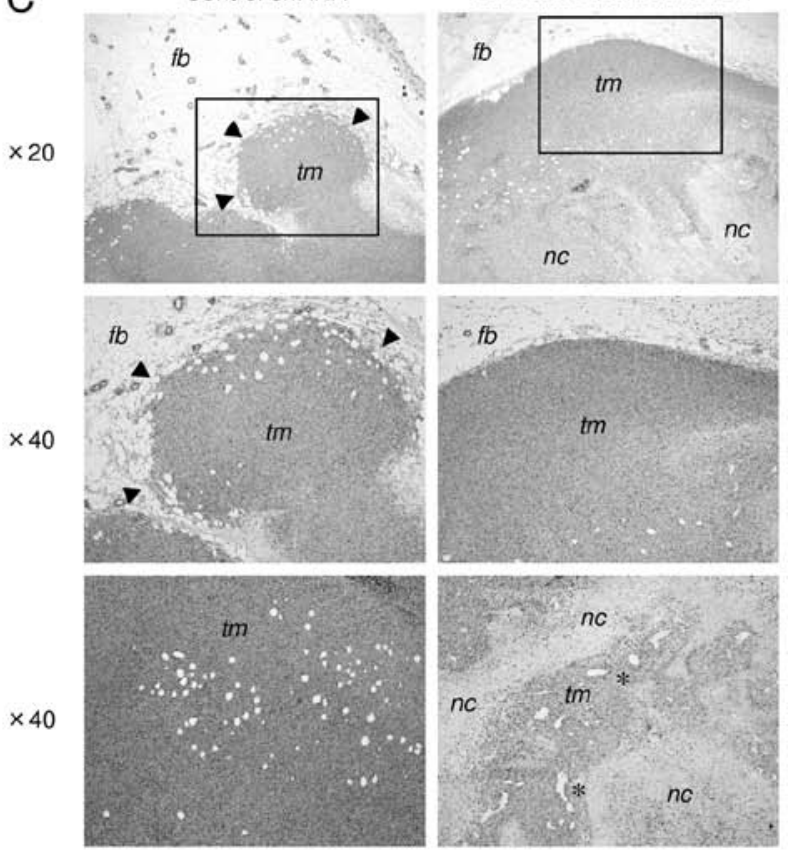

Figure 5. Suppression of $C Y P 24 A 1$ expression inhibits tumorigenicity in vivo. (A) MDA-MB-231 cells transfected with $C Y P 24 A 1$-specific shRNAs grew significantly slower than did control cells. (B) Representative tumors developed in mice 18 days post-injection (upper panel) and their weights upon dissection (lower panel). (C) Histology of tumors (tm) developed from transplanted cells. Note the invasive growth (arrowheads) into surrounding fibrous tissue (fb) in tumors derived from control cells (upper panel). The tumors derived from cells with CYP24A1 suppression showed massive cell necrosis (nc) in the tumor centers (lower panel), while a limited number of tumor cells were viable only locating around the microvasculature $(*)$. The middle panels represent magnifications of the rectangular areas in the upper panels. (D) Apoptosis, Ki-67 labeling, and CD34-positive microvessels were quantitated in tumors developed in mice. ${ }^{*} \mathrm{P}<0.05$ for control cells vs. cells transfected with $C Y P 24 A 1$-specific shRNA.

showing a markedly decelerated rate of tumor growth (Fig. 5A and B). In addition, the cells with lower metabolic activity showed greater retardation of tumor formation in mammary fat pads. $C Y P 24 A 1$-expressing tumors showed high-grade malignant characteristics, such as invasive growth into the surrounding tissue (Fig. 5C). However, CYP24A1-suppressed 
tumors did not show invasiveness, and the tumor tissues underwent massive necrosis, which was accompanied by increased apoptosis and reduced mitosis (Fig. 5D). These findings are partially explained by the ability of $C Y P 24 A 1$ suppression to cause upregulation of the anti-invasion marker PDLIM2 (Fig. 2D). Histological examinations also revealed a marked decrease of CD34-positive microvascular components in tumors developed from CYP24Al-silenced cells (Fig. 5D). Consistently, cancer cells with CYP24A1 downregulation showed significantly lower expression levels of pro-angiogenic genes, such as angiopoietin (Fig. 2B). This observation was in good agreement with evidence that vitamin D can inhibit angiogenesis (6).

\section{Discussion}

Much attention has been paid to the roles of $1 \alpha, 25(\mathrm{OH})_{2} \mathrm{D}_{3}$ in many cell types because of its pleiotropic anticancer effects. Here, we unveiled a mechanistic link between CYP24A1mediated intracellular vitamin D metabolism and enhanced tumorigenicity. Our observations are consistent with accumulating evidence, demonstrating that active vitamin D metabolism occurred in different types of cancer cells and that elevated CYP24A1 expression was detectable in various malignancies (7-9). CYP24A1 expression affected the expression of a wide variety of signaling molecules associated with the carcinogenic events, modulating the gene-expression profile in tumor cells to potentially confer unique cell-survival properties to the affected cells. These findings are supported by epidemiological data showing that vitamin $\mathrm{D}$ deficiency could increase the risk for cancer $(14,15)$. The data indicated that CYP24A1-mediated vitamin D insufficiency contributed the development of breast neoplasia, implicating $C Y P 24 A 1$ as a candidate oncogene.

Our unpublished data revealed that $C Y P 24 A 1$ silencing conferred targeted cells with increased susceptibility to several differently acting apoptogens in various cell types. As a result, $C Y P 24 A 1$ downregulation suppressed colony formation in vitro in several breast carcinoma cell lines, regardless of expression of the ER. In addition, we found that CYP24A1 overexpression could transform NIH/3T3 fibroblasts, causing them to show enhanced focus formation in confluent cultures, as also observed following overexpression of the KRAS oncogene in these cells. However, $C Y P 24 A 1$ overexpression in non-transformed breast epithelial MCF-10A cells did not cause anchorage-independent growth in soft agar (data not shown). These results indicated that the vitamin D metabolic activity promoted by CYP24A1 stimulated oncogenesis in breast carcinoma cells.

Unexpectedly, we did not observe elevated CYP24A1 expression in primary breast carcinomas by immunohistochemistry, using different types of tissue microarrays and archived formalin-fixed, paraffin-embedded tissue specimens, whereas CYP24A1 expression was shown to be elevated in breast neoplasia (16). In addition, we found no significant increase in the CYP24Al copy number by fluorescent in situ hybridization, although high copy-number gain was reported to be a key determinant of CYP24A1 overexpression (17). We cannot explain these discrepant observations; however, it is clear that several commercially available CYP24A1 antibodies and $C Y P 24 A 1$ probes did not function properly with tissue specimens under our reaction conditions. Alternatively, the possibility remains that breast cancers do not have increased CYP24A1 expression.

Informatics data revealed the presence of 2 vitamin D-responsive elements (VDREs) located immediately upstream of the $C Y P 24 A 1$ gene. Data from promoter studies have also demonstrated that multiple VDRE sites and potential Sp1 sites are synergistically involved in the regulation of CYP24Al expression (18). As a corollary, transcriptional complexity should be noted in understanding the regulatory mechanism of CYP24A1 overexpression during carcinogenesis (19). Therefore, future studies are warranted to better understand the regulatory mechanism of $C Y P 24 A 1$ in neoplasia of the breast.

Our present findings showed that many genes involved in tumorigenesis were modulated to favor cell survival when CYP24A1 was constitutively expressed. Based on the gain-offunction effect of CYP24A1 on carcinogenesis, recapitulation of CYP24A1 expression in cancer cells would provide a selective growth advantage to these cells, thereby enabling evasion of normal apoptotic mechanisms. Therefore, strategies that decrease the activity of CYP24A1 may be an important means of increasing the sensitivity of cancer cells to pro-apoptotic therapies.

\section{Acknowledgements}

This study was supported in part by a grant from the Grantsin-Aid for Scientific Research program from the Japan Society for the Promotion of Science.

\section{References}

1. Albertson DG, Ylstra B, Segraves R, Collins C, Dairkee SH, Kowbel D, Kuo WL, Gray JW and Pinkel D: Quantitative mapping of amplicon structure by array CGH identifies CYP24 as a candidate oncogene. Nat Genet 25: 144-146, 2000.

2. Kallioniemi A, Kallioniemi OP, Piper J, Tanner M, Stokke T, Chen L, Smith HS, Pinkel D, Gray JW and Waldman FM: Detection and mapping of amplified DNA sequences in breast cancer by comparative genomic hybridization. Proc Natl Acad Sci USA 91: 2156-2160, 1994.

3. Hodgson JG, Chin K, Collins C and Gray JW: Genome amplification of chromosome 20 in breast cancer. Breast Cancer Res Treat 78: 337-345, 2003.

4. Tanner MM, Tirkkonen M, Kallioniemi A, Holli K, Collins C, Kowbel D, Gray JW, Kallioniemi OP and Isola J: Amplification of chromosomal region 20q13 in invasive breast cancer: Prognostic implications. Clin Cancer Res 1: 1455-1461, 1995.

5. Weiss MM, Snijders AM, Kuipers EJ, Ylstra B, Pinkel D, Meuwissen SG, van Diest PJ, Albertson DG and Meijer GA: Determination of amplicon boundaries at 20q13.2 in tissue samples of human gastric adenocarcinomas by high-resolution microarray comparative genomic hybridization. J Pathol 200: 320-326, 2003.

6. Deeb KK, Trump DL and Johnson CS: Vitamin D signalling pathways in cancer: Potential for anticancer therapeutics. Nat Rev Cancer 7: 684-700, 2007.

7. Mimori K, Tanaka Y, Yoshinaga K, Masuda T, Yamashita K, Okamoto M, Inoue H and Mori M: Clinical significance of the overexpression of the candidate oncogene CYP24 in esophageal cancer. Ann Oncol 15: 236-241, 2004.

8. Parise RA, Egorin MJ, Kanterewicz B, Taimi M, Petkovich M Lew AM, Chuang SS, Nichols M, El-Hefnawy $\mathrm{T}$ and Hershberger PA: CYP24, the enzyme that catabolizes the antiproliferative agent vitamin D, is increased in lung cancer. Int J Cancer 119: 1819-1828, 2006. 
9. Tannour-Louet M, Lewis SK, Louet JF, Stewart J, Addai JB, Sahin A, Vangapandu HV, Lewis AL, Dittmar K, Pautler RG, et al: Increased expression of CYP24A1 correlates with advanced stages of prostate cancer and can cause resistance to vitamin $\mathrm{D}_{3}$-based therapies. FASEB J 28: 364-372, 2014.

10. Townsend K, Banwell CM, Guy M, Colston KW, Mansi JL, Stewart PM, Campbell MJ and Hewison M: Autocrine metabolism of vitamin D in normal and malignant breast tissue. Clin Cancer Res 11: 3579-3586, 2005.

11. Masuda S, Kaufmann M, Byford V, Gao M, St-Arnaud R, Arabian A, Makin HL, Knutson JC, Strugnell S and Jones G: Insights into Vitamin D metabolism using cyp24 over-expression and knockout systems in conjunction with liquid chromatography/mass spectrometry (LC/MS). J Steroid Biochem Mol Biol 89-90: 149-153, 2004.

12. Vanoirbeek E, Eelen G, Verlinden L, Carmeliet G, Mathieu C, Bouillon R, O'Connor R, Xiao G and Verstuyf A: PDLIM2 expression is driven by vitamin $\mathrm{D}$ and is involved in the proadhesion, and anti-migration and -invasion activity of vitamin D. Oncogene 33: 1904-1911, 2014.

13. Cao Z, West C, Norton-Wenzel CS, Rej R, Davis FB, Davis PJ and Rej R: Effects of resin or charcoal treatment on fetal bovine serum and bovine calf serum. Endocr Res 34: 101-108, 2009.

14. Schwartz GG and Blot WJ: Vitamin D status and cancer incidence and mortality: Something new under the sun. J Natl Cancer Inst 98: 428-430, 2006.
15. Spina CS, Tangpricha V, Uskokovic M, Adorinic L, Maehr H and Holick MF: Vitamin D and cancer. Anticancer Res 26A: 2515-2524, 2006

16. Lopes N, Sousa B, Martins D, Gomes M, Vieira D, Veronese LA, Milanezi F, Paredes J, Costa JL and Schmitt F: Alterations in Vitamin D signalling and metabolic pathways in breast cancer progression: A study of VDR, CYP27B1 and CYP24A1 expression in benign and malignant breast lesions. BMC Cancer 10 : 483,2010

17. Höbaus J, Hummel DM, Thiem U, Fetahu IS, Aggarwal A, Müllauer L, Heller G, Egger G, Mesteri I, Baumgartner-Parzer S, et al: Increased copy-number and not DNA hypomethylation causes overexpression of the candidate proto-oncogene CYP24A1 in colorectal cancer. Int J Cancer 133: 1380-1388, 2013.

18. Tashiro K, Ishii C and Ryoji M: Role of distal upstream sequence in vitamin D-induced expression of human $C Y P 24$ gene. Biochem Biophys Res Commun 358: 259-265, 2007.

19. Pike JW and Meyer MB: Regulation of mouse Cyp24a1 expression via promoter-proximal and downstream-distal enhancers highlights new concepts of 1,25-dihydroxyvitamin $\mathrm{D}(3)$ action. Arch Biochem Biophys 523: 2-8, 2012. 